\title{
Atrial fibrillation is related to higher mortality in COVID-19/SARS-CoV-2 pneumonia infection
}

\author{
Andrea Denegri ${ }^{1}\left({ }^{\circ}, M^{2}\right.$ arianna Morelli ${ }^{2}$, Giuseppe Pezzuto², \\ Vincenzo Livio Malavasi ${ }^{1}$, Giuseppe Boriani ${ }^{1}$ (D) \\ ${ }^{1}$ Cardiology Division, Department of Biomedical, Metabolic and Neural Sciences, University of Modena \\ and Reggio Emilia, Azienda Ospedaliero-Universitaria di Modena, Modena, Italy \\ ${ }^{2}$ Emergency Department, Azienda Ospedaliero-Universitaria di Modena, Modena, Italy
}

Coronavirus disease 2019 (COVID-19) due to a novel coronavirus (CoV-2) has rapidly spread worldwide, with over 110,7 million cases and 2.4 million deaths have been reported globally as of February $25^{\text {th }}$, with 420,000 new cases and nearly 10,000 new deaths reported over the last 24 hours [1]. Cardiac involvement in COVID-19 patients has been described and associated with worse outcomes [2] and atrial fibrillation (AF) has been correlated with ventilator use and increased mortality [3]. The aim of the present study was to assess the impact of $\mathrm{AF}$ at admission on outcome in all-comer COVID-19 patients admitted to the Emergency Department of Modena University Hospital.

We retrospectively analyzed the patients diagnosed with COVID-19 pneumonia (symptoms, positive nasopharyngeal swab and typical radiological feature) admitted to the Emergency Department of Modena University Hospital from March the $16^{\text {th }}$ to April the $15^{\text {th }} 2020$, after obtaining local EC approval. Clinical data, including outcome, were extracted from medical records. 12-lead ECGs with $25 \mathrm{~mm} / \mathrm{s}$ and $1 \mathrm{mV} / \mathrm{cm}$ calibration and $0.05-150 \mathrm{~Hz}$ filter setting were recorded and analyzed off-line. Continuous variables were expressed as mean \pm standard deviation while categorical data were expressed as absolute values and proportions. The Fisher exact test and the t-test or the Mann-Whitney U test were applied as appropriate. Survival curves were plotted using the Kaplan-Meier method with log-rank test and COX-regression model was applied. Analyses were performed with SPSS, Statistical Package for Social Science) software (v26, SPSS Inc., Chicago, IL, USA). For all the statistical analyses, a two tailed $\mathrm{p}<0.05$ was considered significant.

Atrial fibrillation patients $(30 / 201,14.9 \%)$ were older $(78.5 \pm 12.6$ vs. $66.8 \pm 14.4, \mathrm{p}<0.001)$, with a more complex cardiovascular history (hypertension [86.7\% vs. $51.2 \%, \mathrm{p}<0.001]$, coronary artery disease [CAD, $46.7 \%$ vs $12.4 \%$, p < 0.001$]$, peripheral artery disease $[20.0 \%$ vs. $5.9 \%$, $\mathrm{p}=0.019]$ and chronic kidney disease [CKD 30.0\% vs. $10.1 \%, \mathrm{p}=0.006]$ ) and positive myocardial injury markers (troponin I $1042.7 \pm 4534.5$ vs. $55.6 \pm 172.3 \mathrm{ng} / \mathrm{L})$. The mean $\mathrm{CHA}_{2} \mathrm{DS}_{2} \mathrm{VASc}$ score was $4.23 \pm 1.71$ vs. $2.27 \pm 1.76, \mathrm{p}<0.001$ (Fig. $1 \mathrm{~A}$ ). $\mathrm{AF}$-patients presented a 5 -fold higher risk of mortality (odds ratio [OR] 5.33, 95\% confidence interval [CI] 2.34-12.17, $\mathrm{p}<0.001$ ), which rose 12 -fold (OR 12.74, 95\% CI 3.65-44.48, p < 0.001) for those with AF at 12-lead electrocardiogram (ECG) at admission. Patients with the highest $\mathrm{CHA}_{2} \mathrm{DS}_{2} \mathrm{VASc}$ score presented the highest rate of mortality (Fig. 1B). After adjustment for confounding factors such as age, sex, hypertension, CAD and $\mathrm{CKD}, \mathrm{AF}$ was confirmed to be an independent predictor of all-cause mortality (hazard ratio 0.48 , 95\% CI 0.24-0.93, p = 0.030; Fig. 1C).

Electrocardiogram alterations, including AF, are quite common in COVID-19 infection and related to worse clinical outcome [4]. AF is detected in COVID-19 patients at 12-lead baseline ECG in up to one fifth of the cases [5]. Particularly, new-

Address for correspondence: Dr. Andrea Denegri, MD, PhD, FESC, Cardiology Division, Department of Biomedical, Metabolic and Neural Sciences, University of Modena and Reggio Emilia, Azienda Ospedaliero-Universitaria di Modena, Largo del Pozzo 71, 41125, Modena, Italy, tel: +393286574387, e-mail: denegri.andrea@aou.mo.it

Received: 28.02.2021 Accepted: 30.07.2021 Early publication date: 10.09.2021

This article is available in open access under Creative Common Attribution-Non-Commercial-No Derivatives 4.0 International (CC BY-NC-ND 4.0) license, allowing to download articles and share them with others as long as they credit the authors and the publisher, but without permission to change them in any way or use them commercially. 


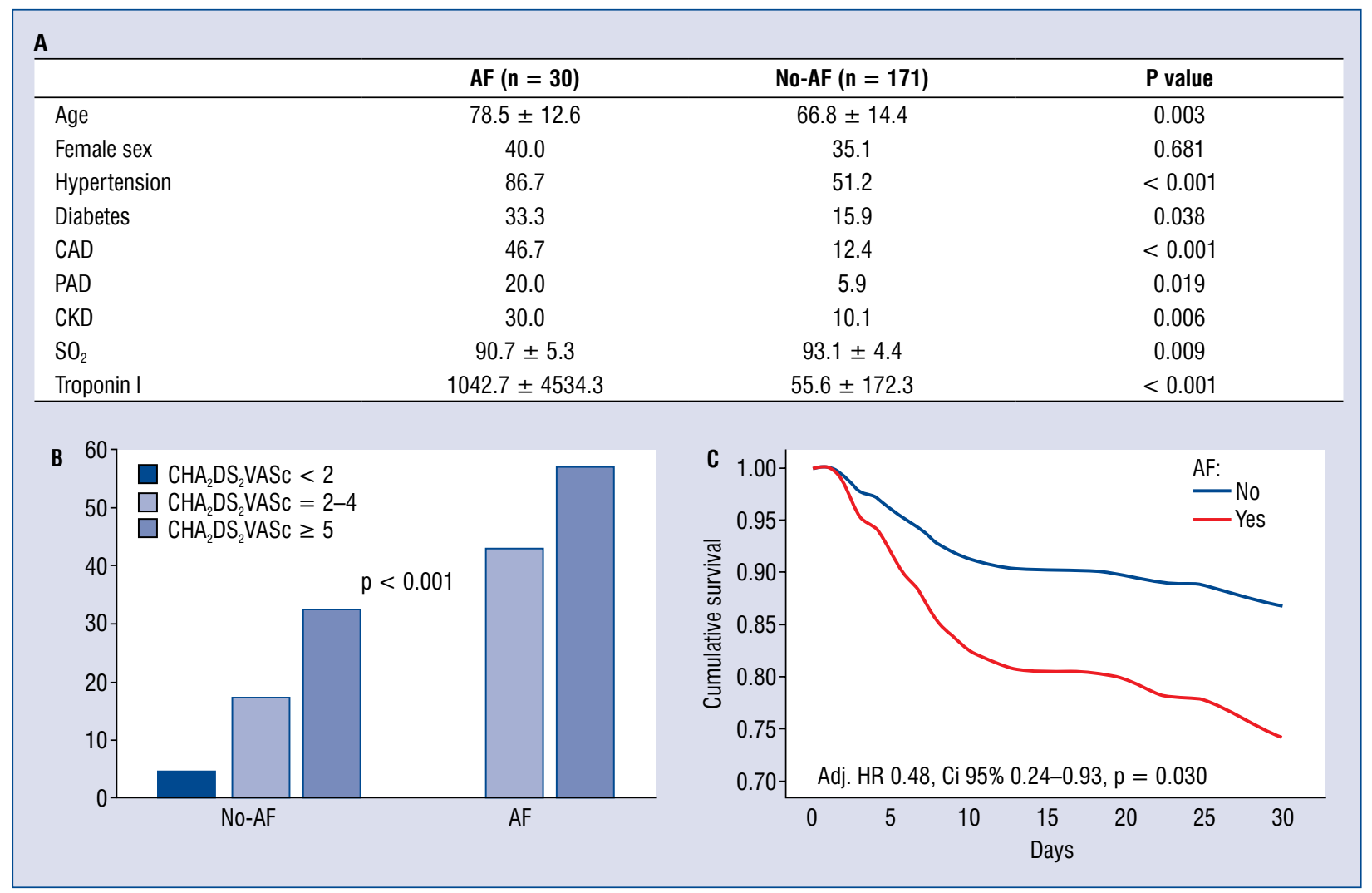

Figure 1. A. Baseline characteristics; B. 30-day mortality rate according to $\mathrm{CHA}_{2} \mathrm{DS}_{2} \mathrm{VASc}$ score in atrial fibrillation (AF)and no-AF-patients; C. 30-day mortality according to presence/absence of AF after adjustment for age, sex, history of hypertension, coronary artery disease (CAD) and chronic kidney disease (CKD); PAD — peripheral artery disease; $\mathrm{HR}$ - hazard ratio; $\mathrm{Cl}$ - confidence interval.

onset $\mathrm{AF}$ has been related to worse cardiovascular outcome [6]. These patients may benefit from a more intensive treatment for primary prevention of thrombo-embolic events, representing, among all cardiovascular-diseased COVID-19 patients, a high-risk group. Although further studies from larger population cohorts are required to assess the prognostic role of AF in COVID-19, these patients are potentially fragile and vulnerable, characterized by a higher risk of death, thus suitable for a careful clinical monitoring and more intensive treatment [7]. The $\mathrm{CHA}_{2} \mathrm{DS}_{2} \mathrm{VASc}$ score may be useful in further risk stratification of COVID-19 [8] and early identification of AF with routine ECG evaluation may be helpful in risk assessment and therapy approach individualization.

As of today, COVID-19 infection treatment is based on supportive therapies and mechanical ventilation. Despite our small cohort size, a higher 30-day mortality was observed in COVID-19 patients with $\mathrm{AF}$ at baseline 12-lead ECG; thus, routine ECG evaluation, in COVID-19 pneumonia, may be helpful in risk stratification and therapeutic approach targeting.

\section{Conflict of interest: None declared}

\section{References}

1. https://www.who.int/docs/default-source/coronaviruse/situationreports/20200928-weekly-epi-update.pdf?sfvrsn=9e354665_6.

2. Huang C, Wang Y, Li X, et al. Clinical features of patients infected with 2019 novel coronavirus in Wuhan, China. Lancet. 2020; 395(10223): 497-506, doi: 10.1016/s0140-6736(20)30183-5.

3. Elias P, Poterucha TJ, Jain SS, et al. The prognostic value of electrocardiogram at presentation to emergency department in patients with COVID-19. Mayo Clin Proc. 2020; 95(10): 2099-2109, doi: 10.1016/j.mayocp.2020.07.028, indexed in Pubmed: 33012341.

4. Denegri A, Pezzuto G, D'Arienzo M, et al. Clinical and electrocardiographic characteristics at admission of COVID-19/ SARS-CoV2 pneumonia infection. Intern Emerg Med. 2021; 16(6): 1451-1456, doi: 10.1007/s11739-020-02578-8, indexed in Pubmed: 33398608. 
5. Bertini M, Ferrari R, Guardigli G, et al. Electrocardiographic features of 431 consecutive, critically ill COVID-19 patients: an insight into the mechanisms of cardiac involvement. Europace. 2020; 22(12): 1848-1854, doi: 10.1093/europace/euaa258, indexed in Pubmed: 32944767.

6. Pardo Sanz A, Salido Tahoces L, Ortega Pérez R, et al. New-onset atrial fibrillation during COVID-19 infection predicts poor prognosis. Cardiol J. 2021; 28(1): 34-40, doi: 10.5603/ CJ.a2020.0145, indexed in Pubmed: 33140386.
7. Sanchis-Gomar F, Perez-Quilis C, Lavie CJ. Should atrial fibrillation be considered a cardiovascular risk factor for a worse prognosis in COVID-19 patients? Eur Heart J. 2020; 41(32): 3092-3093, doi: 10.1093/eurheartj/ehaa509, indexed in Pubmed: 32688380.

8. Ruocco G, McCullough PA, Tecson KM, et al. Mortality risk assessment using CHA(2)DS(2)-VASc scores in patients hospitalized with coronavirus disease 2019 infection. Am J Cardiol. 2020; 137: 111-117, doi: 10.1016/j.amjcard.2020.09.029, indexed in Pubmed: 32991860. 